\title{
Communication
}

\section{Novel Anisotropic Ductility of a High Strength Annealed Ti-20Zr-6.5Al-4V Alloy}

\author{
Bing Zhang *, Xing Zhang, Yuanzhi Jia, Xinyu Zhang, Mingzhen Ma, Riping Liu and Qin Jing * \\ State key laboratory of Metastable Materials Science and Technology, Yanshan University, \\ Qinhuangdao 066004, China; xingzhang9024@yeah.net (X.Z.); ysujyz@126.com (Y.J.); \\ xyzhang@ysu.edu.cn (X.Z.); mz550509@ysu.edu.cn (M.M.); riping@ysu.edu.cn (R.L.) \\ * Correspondence: zhangbing@ysu.edu.cn (B.Z.); jingqin@ysu.edu.cn (Q.J.); Tel.: +86-335-806-4504 (Q.J.)
}

Received: 4 March 2018; Accepted: 29 March 2018; Published: 30 March 2018

Abstract: In this work, we investigate the mechanical properties of an annealed high strength Ti-20Zr-6.5Al-4V alloy in uniaxial tensile tests in different directions. The results show that the alloy exhibits obvious anisotropic ductility in different directions, while the tensile strength of the alloy remains almost unchanged. This phenomenon is closely related to $\alpha$ laths with similar orientations along the prior- $\beta$ grain boundaries. These $\alpha$ laths significantly affect the initiation and propagation of cracks when the alloy reaches its yield limit, thereby affecting the ductility of the alloy, such that it exhibits anisotropic ductility.

Keywords: Ti-20Zr-6.5Al-4V alloy; uniaxial tensile; similarly orientated $\alpha$ laths; crack; ductility anisotropy

\section{Introduction}

Ti alloys are applied in many fields due to their many excellent properties such as exceptional strength-to-weight ratio, high performance at elevated temperatures, high hardenability, outstanding corrosion resistance, good biocompatibility and excellent fatigue propagation properties [1-5]. However, their poor tribological properties and high thermal expansion coefficient restrict their application [6,7], especially as structural materials in the extreme space environment.

Recently, Zr has been noted for its ability to improve the mechanical properties of Ti alloys and a new Ti alloy comprising Ti-20Zr-6.5Al-4V (wt \%, shortened to 20Zr hereafter) has been developed [8]. The alloy exhibits higher tensile strength and hardness than the well-known Ti-6Al-4V alloy [8,9]. Thus, $20 \mathrm{Zr}$ alloy is an excellent candidate as a structural material for application in the space environment.

In practice, the anisotropy of mechanical properties must be considered when designing and building structural components. Previously, researchers have conducted a series of studies on the 20Zr alloy [10-14]. However, as yet, no study has focused on the anisotropy of the mechanical properties of $20 \mathrm{Zr}$ alloy. As a candidate structural material for use in the space environment, alloys must be heavily tested with respect to their reliability. Thus, it is necessary to investigate the anisotropy of mechanical properties of this alloy.

Most studies of the anisotropy of mechanical properties select the rolled or extruded state as the study object because it typically reveals the obvious anisotropy of mechanical properties $[15,16]$. However, in this study, we selected $20 \mathrm{Zr}$ alloy annealed at $750{ }^{\circ} \mathrm{C}$ for $2 \mathrm{~h}$ to investigate the anisotropy of the mechanical properties because it exhibits a balance of high strength and ductility [13]. This alloy is in a dual $(\alpha+\beta)$ phase in this condition. The results from this study may help us to understand the failure process of the $20 \mathrm{Zr}$ alloy, and give us some useful information to enhance the mechanical properties of the alloy. 


\section{Materials and Methods}

The preparation process of the 20Zr alloy used in this study has been presented in elsewhere [13]. The alloy sheet used in the experiment was cut lengthwise from a long round bar. The round bar has been processed by forging prior to the annealing treatment. We cut the tensile test samples from the same alloy sheet with certain angles between the center axis of the samples and the alloy sheet, as shown in the inset of Figure 1a. According to these angles, we labeled the samples as A0, A30, A60 and A90. These specimens were dog-bone shaped with a gauge size of $2 \times 3 \times 15 \mathrm{~mm}^{3}$. We performed all the tensile tests on an Instron 5982 mechanical test system with a crosshead speed of $0.375 \mathrm{~mm} \mathrm{~min}^{-1}$. We repeated the tensile test for each angle three times to reduce random error. We observed the fracture surfaces of these samples using a Hitachi S3400N scanning electron microscope (SEM, Hitachi, Tokyo, Japan). To identify the microstructure details of the samples, we examined the cross sections perpendicular to the tensile direction using an EDAX-TSL electron backscatter diffraction (EBSD) system (Ametek, Berwyn, PA, USA). In addition, to identify the propagation paths of the cracks in the tensile testing samples, we cut a fractured sample longitudinally along the tensile direction and examined it by EBSD. Using a standard metallographic procedure, we mechanically polished all the EBSD samples to a $0.5-\mu \mathrm{m}$ diamond paste, then further improved the samples by vibration polishing. Lastly, we realized the required surface finish by performing electro-polishing in a solution of $10 \%$ perchloric acid, $20 \%$ butyl cellosolve, and $70 \%$ methanol at $20 \mathrm{~V}$ and $-20{ }^{\circ} \mathrm{C}$. We performed EBSD mapping at an operating voltage of $20 \mathrm{kV}$ at a working distance of approximately $15 \mathrm{~mm}$. We then analyzed the EBSD data using TSL OIM Analysis 7 software.
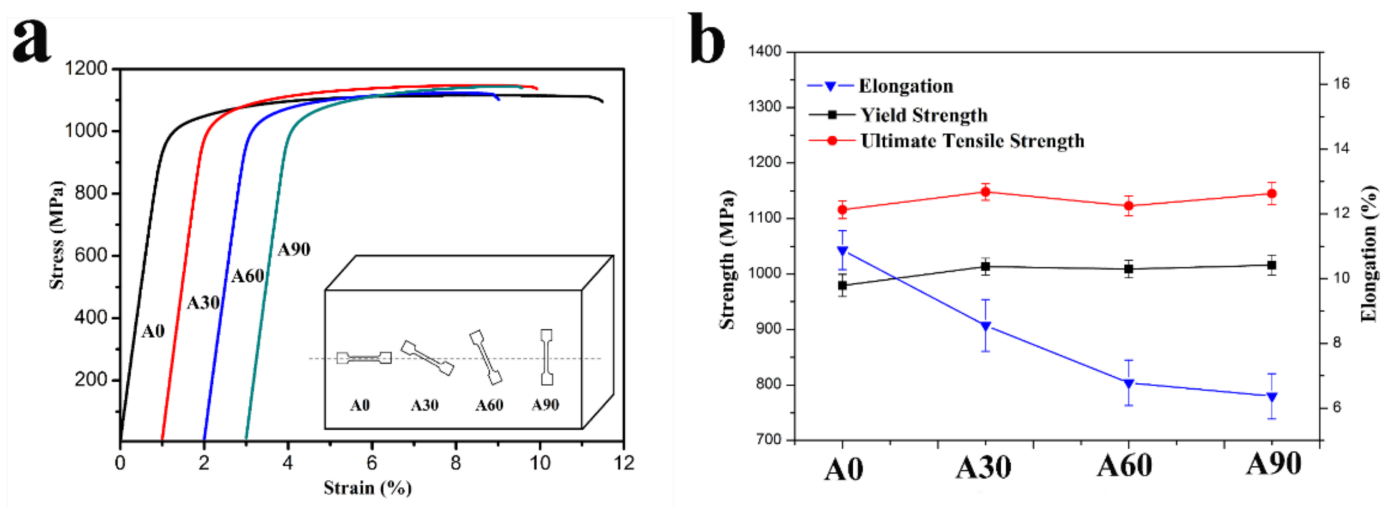

Figure 1. Uniaxial tensile test results of the different-direction samples. (a) Engineering stress-strain curves of the samples. Inset illustrates the sample cut method used. (b) Elongation, yield strength, and ultimate tensile strength of the samples.

\section{Results and Discussion}

Figure 1a presents the tensile curves of the samples with different angles, which shows only small variations in the ultimate tensile and yield strengths of the samples. The tensile and yield strengths are about $1100 \mathrm{MPa}$ and $1000 \mathrm{MPa}$, respectively. Therefore, we can consider the strength of the samples to be unchanged. However, we note that the elongation of the samples varies over a wide range (Figure $1 \mathrm{~b}$ ). This elongation shows a decreasing trend as the angles increase. The elongation of the samples decreased from $10.8 \%$ in A0 to $6.1 \%$ in A90. This $43.5 \%$ reduction in elongation (ductility) indicates that the annealed $20 \mathrm{Zr}$ alloy exhibits anisotropic ductility.

To identify the mechanism of the fracture, we used SEM to observe the fracture surface of the different-direction samples. Figure 2 shows the typical morphologies of cracks that appeared in the fracture surface of these samples. We noted that these cracks tend to initiate at and extend along the prior- $\beta$ grain boundaries. In addition, some $\alpha$ laths with a similar orientation were distributed along 
the cracks. The process of determining $\alpha$ laths has been described in previous work [13]. The $\alpha$ laths on the fracture surface can be determined by comparing the size and morphology.
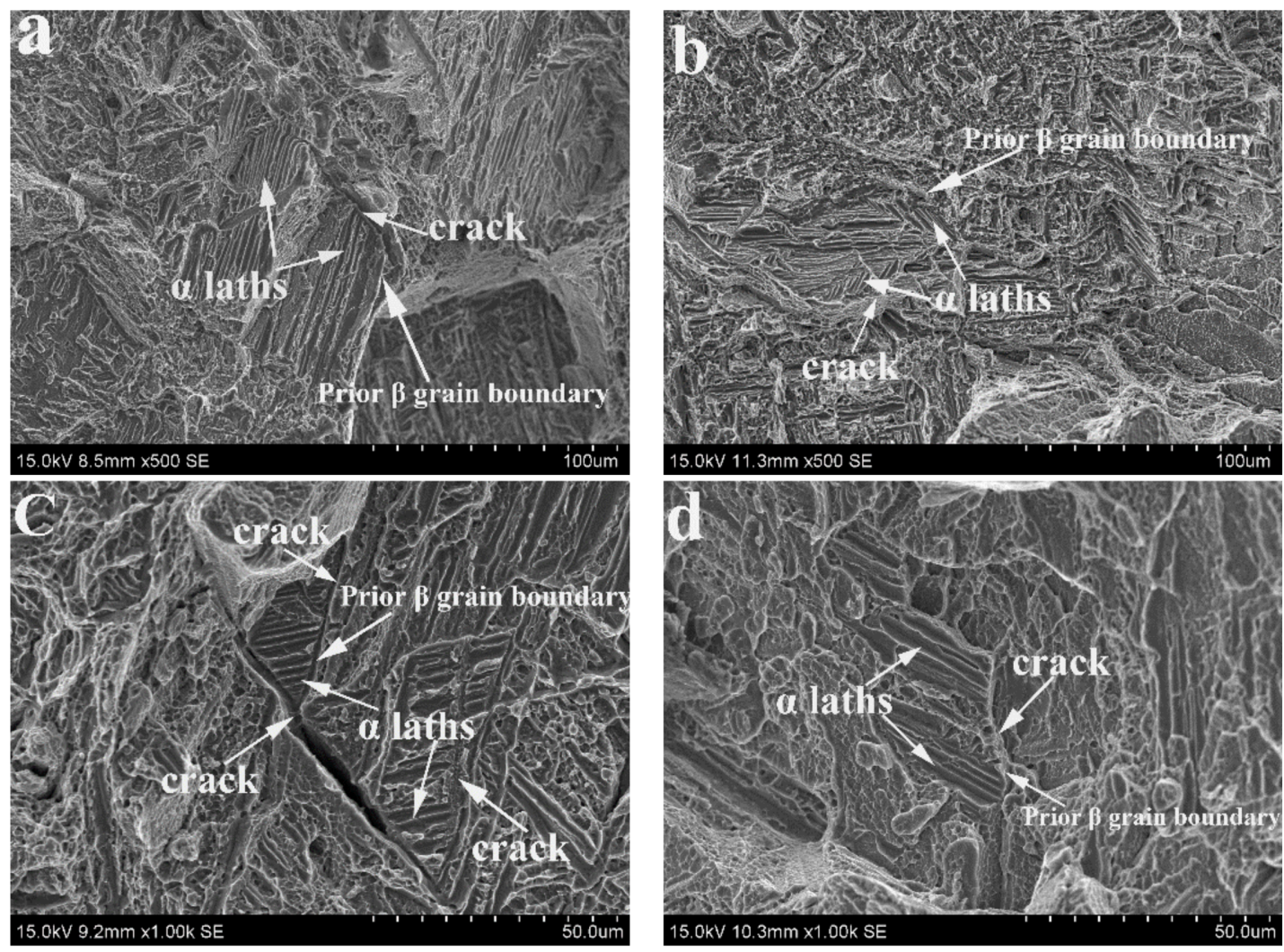

Figure 2. Typical morphologies of the cracks on the fracture surface of the different-direction samples after tensile testing: (a) A0; (b) A30; (c) A60; and (d) A90.

We investigated the microstructure of the samples prior to the tensile test using EBSD, the results of which are shown in Figure 3. The inverse pole figure (IPF) maps show that in both samples, there are some $\alpha$ laths with similar orientations precipitated along the prior- $\beta$ grain boundaries. In addition, the orientations of these similarly orientated $\alpha$ laths areas are different from each other.

Material properties have been found to be significantly affected by texture [17]. To reveal the texture of the samples in different directions, we use pole figures to characterize the texture of $\alpha$ phases $(87.3 \%$, in volume fraction) in the samples. Figure 4 shows $\{0002\},\{10 \overline{1} 0\}$ and $\{2 \overline{11} 0\}$ pole figures of the samples in different directions as shown in Figure 3, whereby the tensile direction is parallel to the normal direction (ND). It can be seen that the maximum texture intensity shows a tendency to decrease and then increase with increase in the angles between the center axis of the samples and the alloy sheet surface. Specifically, the maximum texture intensity of samples A0, A30, A60, and A90 are 22.629 MRD (multiple random distributions), $12 \mathrm{MRD}, 10.956 \mathrm{MRD}$, and $16.635 \mathrm{MRD}$, respectively. In \{0002\} pole figure of sample A0, there are several texture components with high intensities. Besides a strong basal fiber texture (about $21 \mathrm{MRD}$, marked with T1) of about $15^{\circ}$ shift from ND toward A2, the other texture components formed a parabolic shape. In sample A30, a basal fiber texture with a relatively low intensity (about $5 \mathrm{MRD}$, marked with T2) can be seen, and a strong texture component (about $12 \mathrm{MRD}$, marked with T3) rotates around ND at about $-10^{\circ}$ from A2 to A1. Besides these texture components, a component of relatively low intensity (about 7 MRD, marked with T4) rotates about $-10^{\circ}$ around $\mathrm{ND}$ from $\mathrm{A} 1$ to $\mathrm{A} 2$. In addition, five texture components with relatively low intensities around the basal texture component are formed in the $\{0002\}$ pole figure. There is a complex texture state in A60, in which many texture components are formed. A relatively weak basal fiber texture 
(about 7 MRD, marked with T5) shifts about $20^{\circ}$ from ND toward A1, and a relatively strong texture component (about 10 MRD, marked with T6) shifts about $65^{\circ}$ from ND toward A2 in $\{0002\}$ figure. In sample A90, a relatively strong basal fiber texture (about $10 \mathrm{MRD}$, marked with T7) shifts about $15^{\circ}$ from ND toward A1, and a relatively weak texture component (about 7 MRD, marked with T8) rotates about $10^{\circ}$ around ND from A2 to A1. The other texture components formed a parabolic shape similar to the texture components formed in sample A0. The numerous texture components that appear in the samples of different directions are related to the variants selection during the $\beta \rightarrow \alpha$ transition. The similar $\alpha$ laths orientations are attributed to the high intensity of the texture components.
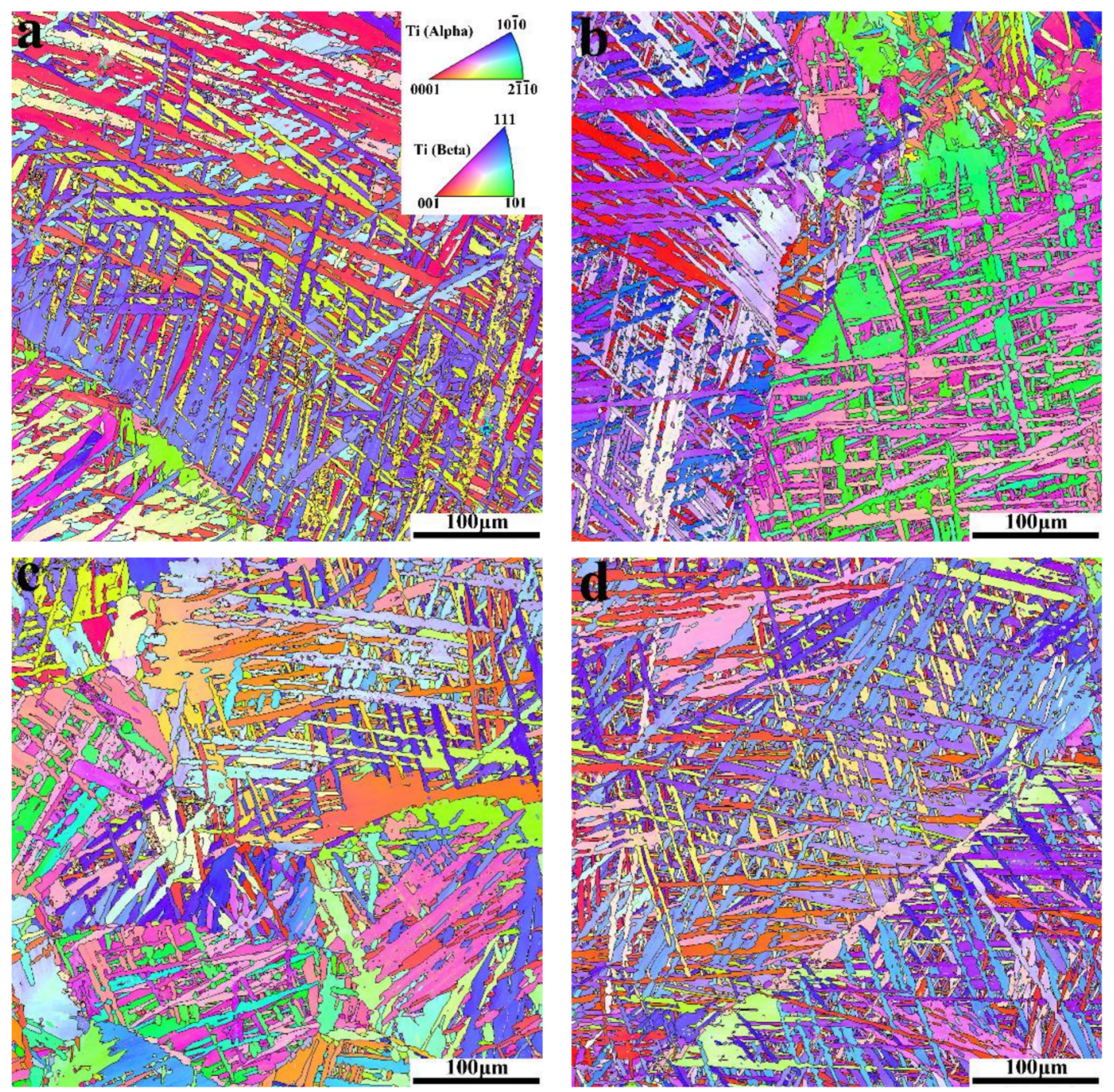

Figure 3. IPF maps of the different-direction samples: (a) A0; (b) A30; (c) A60; and (d) A90. 


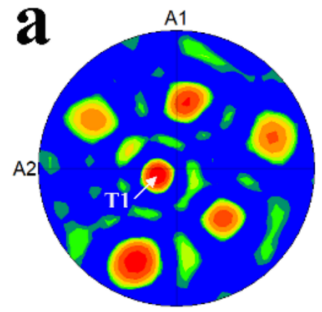

0002
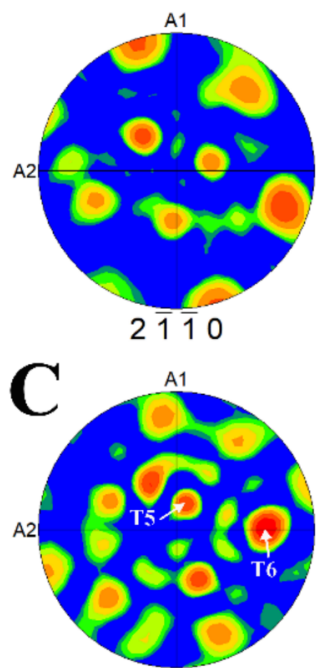

0002

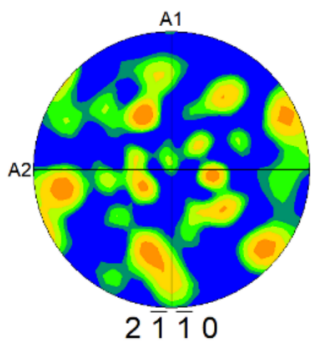

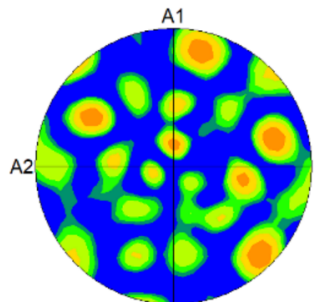

1010
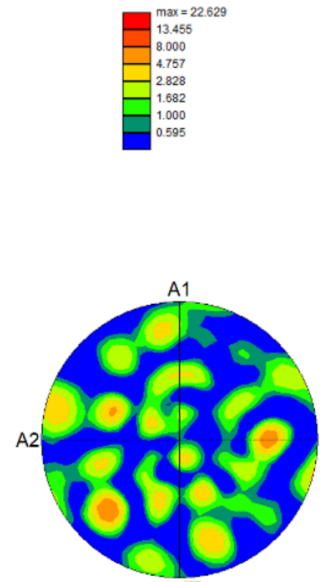

1010

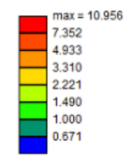

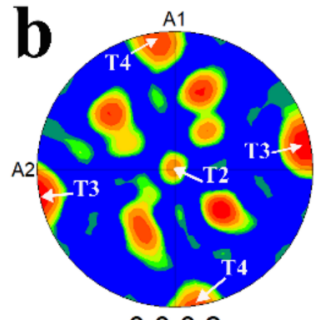

0002

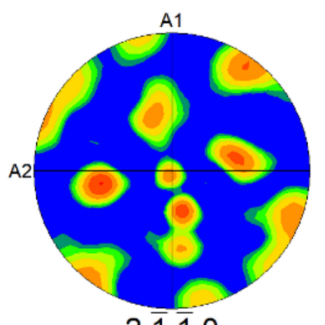

$2 \overline{1} \overline{1} 0$

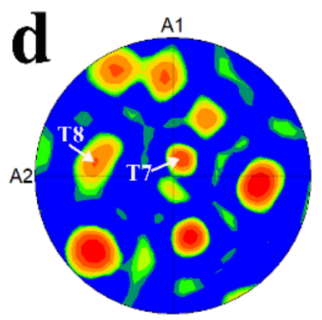

0002

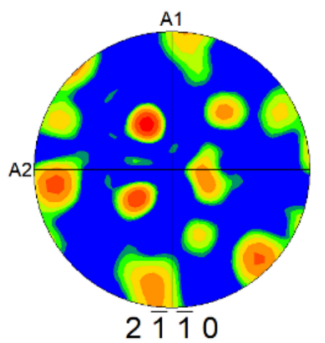

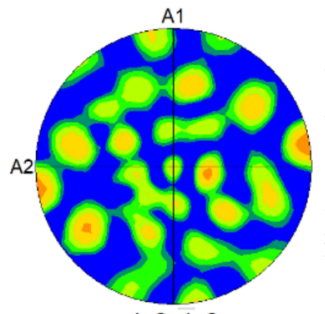

1010
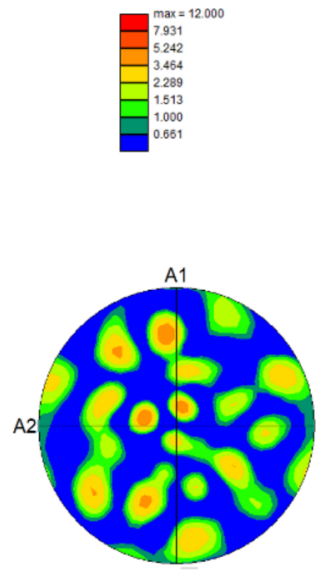

1010

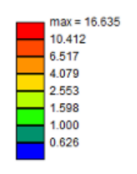

Figure 4. Pole figures of the samples in different-directions: (a) A0; (b) A30; (c) A60; and (d) A90.

To identify the crack propagation paths, we also used EBSD to examine the fractured sample after conducting the tensile test. As shown in Figure 5a, in image quality (IQ) map, the crack originated from the prior- $\beta$ grain boundary and extended through the parallel $\alpha$ lath areas. Previous research shows that $\alpha$ variants inherited from the same parent $\beta$ grain are characterized by specific misorientations linked to the Burgers orientation relation [18]. Thus, EBSD analysis can be employed to identify the prior- $\beta$ grain boundaries. Figure $5 \mathrm{~b}$ shows an overlay of the IPF map and IQ maps, in which we see the parallel $\alpha$ laths areas (marked with A, B, C) have similar orientations (similar colors). These results are consistent with those of the fracture surface analysis. In our previous study of $20 \mathrm{Zr}$ alloy, we observed no twins in the annealed sample following tensile test [13]. As such, slip can be considered to be the dominant deformation mode in the tensile test. In HCP (hexagonal close-packed) alloys, there are three slip systems with a $<\overline{2} 110>$ Burgers vector (a-type), namely, the $\{0001\}$ basal slip, $\{10 \overline{1} 0\}$ prismatic slip, and $\{10 \overline{1} 1\}$ first-order pyramidal slip [19]. Some researchers have shown that a prismatic slip is easier to activate in Ti-6Al-4V alloys at room temperature than the other two slip systems, because prismatic slip has the lowest critically resolved shear stress (CRSS) [19-21]. Therefore, in this study, we considered prismatic slip to be the main slip system at room temperature in $20 \mathrm{Zr}$ alloy, which has a composition similar to Ti-6Al-4V alloy. Figure 5c shows Schmid factors (SF) distribution map of the area shown in Figure 5a. In this map, we set the slip system as prismatic slip. The SF distribution shows that 
some similarly orientated $\alpha$ laths alongside the cracks are blue and green in color (marked with R1), which means that they are in "hard" orientation. This indicates that these areas are less prone to plastic deformation under specific stress conditions, so when subjected to tensile stress, these areas most likely release energy through the formation of cracks. In addition, it can be seen from Figure 5c that the cracks continuously extend through some similarly orientated $\alpha$ laths area (marked with R2) in red color (high-SF-value, "soft" orientation). This is because cracks extend through the similarly orientated $\alpha$ laths areas without change direction, thereby consuming the least amount of energy [22]. This explains why the cracks initiate at the prior- $\beta$ grain boundaries and extend through the similarly orientated $\alpha$ laths areas.
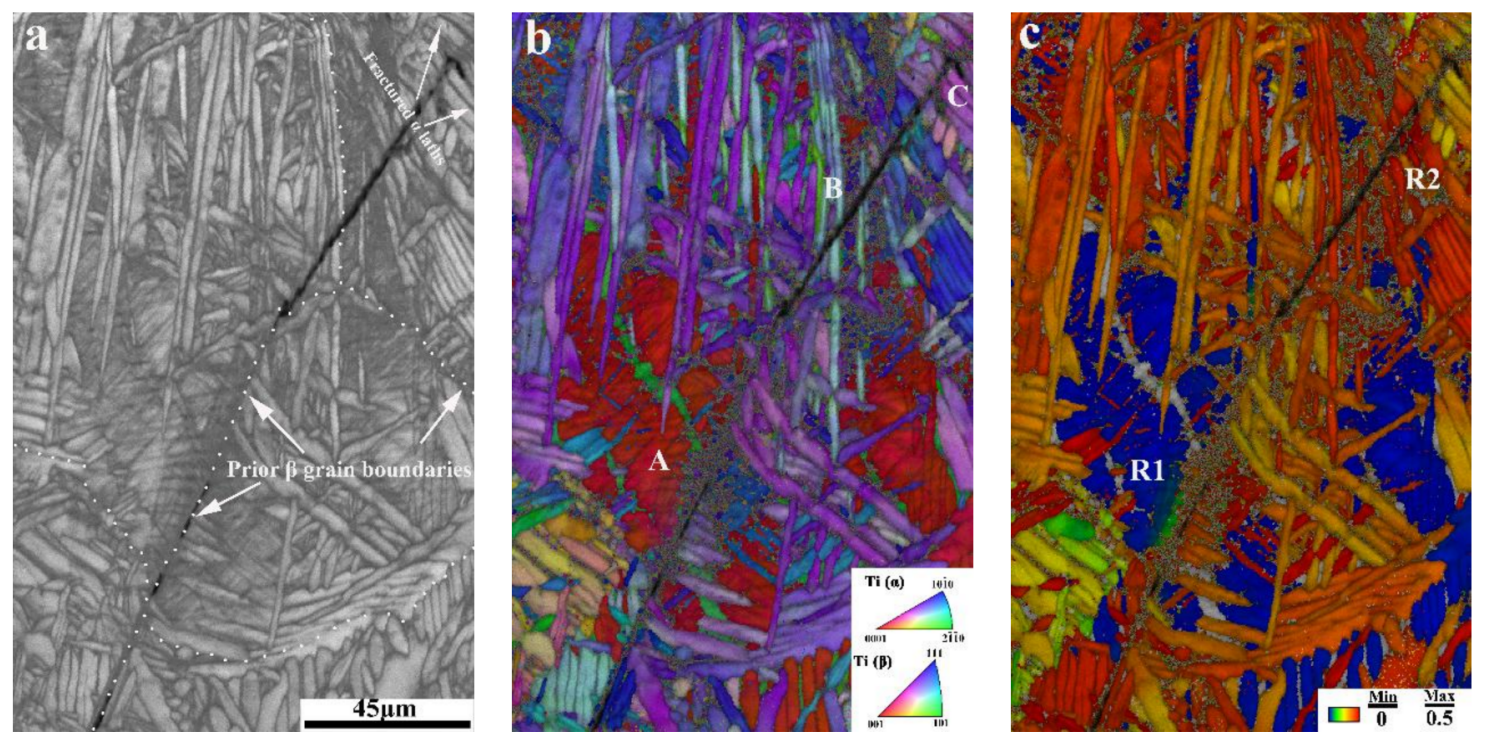

Figure 5. EBSD analysis results of the fractured sample after tensile testing: (a) IQ map; (b) overlay of IQ and IPF maps; (c) overlay of SF distribution and IQ maps.

Figure 6 shows an overlay of the IQ and SF distribution maps of the different-direction samples shown in Figure 3, in which we also set the slip system as prismatic slip. This map shows that in different-directions samples, the numbers and area fractions of the low-SF-value and similarly orientated $\alpha$ lath areas distributed alongside the prior- $\beta$ grain boundaries (indicated by white dot lines) are quite different. This is due to selection of $\alpha$ variants in different directions. As shown in Figure 5, these similarly orientated $\alpha$ lath areas are potential crack initiation and propagation areas, which significantly affect the crack initiation and propagation behavior of the alloy during tensile testing. In sample A0, the cracks are difficult to initiate due to the "soft" orientations (high-SF-value) of the parallel $\alpha$ laths along the prior- $\beta$ grain boundary. When the parallel $\alpha$ laths that distributed on both sides of the prior- $\beta$ grain boundaries are in "hard" orientations (low-SF-value), the cracks are more prone to initiate and spread rapidly. The number of the cracks initiated in sample A30 is less than that in sample A60. And in sample A90, due to the "hard" orientation (low-SF-value) of $\alpha$ laths in both sides of the prior- $\beta$ grain boundary, a long crack along the prior- $\beta$ grain boundary will appear and spread rapidly. Thus, when the tensile stress reaches the yield limit, the number of cracks initiated and the rate of crack propagation vary due to the inconsistent orientations of the $\alpha$ laths along the prior- $\beta$ grain boundaries, which in turn cause the different ductility in different directions, while the tensile strength remains unchanged. 

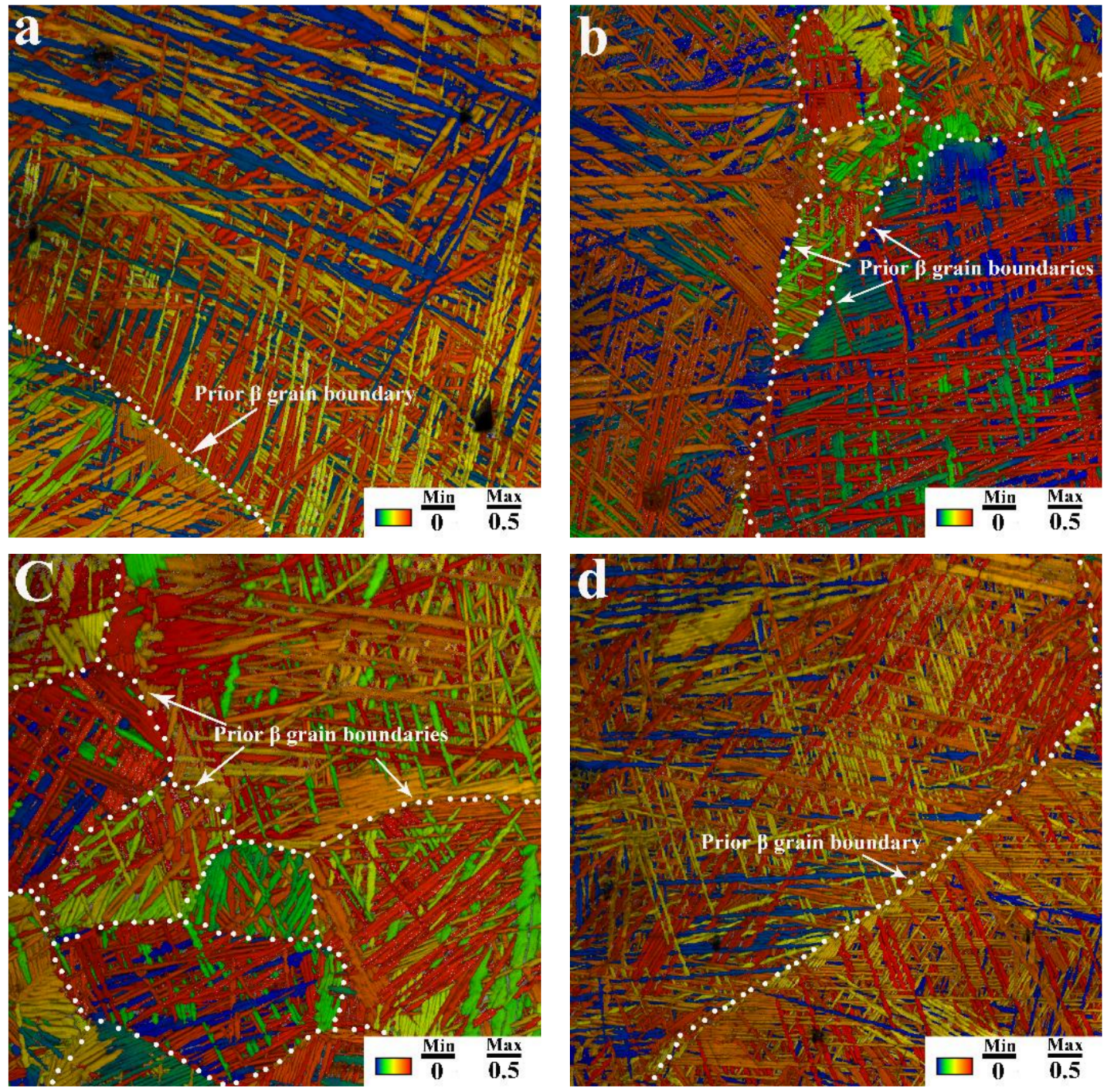

Figure 6. Overlay of SF distribution and IQ maps of the different-direction samples shown in Figure 3: (a) A0; (b) A30; (c) A60; and (d) A90.

In summary, $\alpha$ laths with similar orientations that are distributed along the prior- $\beta$ grain boundaries significantly affect the crack initiation and propagation of the annealed $20 \mathrm{Zr}$ alloy during uniaxial tensile testing, and then affect the ductility of the alloy in different directions, thereby macroscopically exhibiting anisotropic ductility.

Acknowledgments: This work was supported by the SKPBRC (Grant No. 2013CB733000), NSFC (Grant Nos. 51531005/51434008/51571174/51471143), and RPCST of Hebei province (Grant No. QN2014156).

Author Contributions: Bing Zhang and Qin Jing conceived and designed the experiments; Bing Zhang and Xing Zhang performed the experiments; Bing Zhang, Yuanzhi Jia and Xinyu Zhang analyzed the data; Mingzhen Ma and Riping Liu contributed materials; Bing Zhang wrote the paper.

Conflicts of Interest: The authors declare no conflict of interest.

\section{References}

1. Leyens, C.; Peters, M. Titanium and Titanium Alloys: Fundamentals and Applications; Wiley-VCH: Weinheim, Germany, 2006; pp. 1-532. ISBN 3-527-30534-3.

2. Jia, Y.; Liu, R.; Hu, W.; Wang, Z.; Zhang, B.; Liu, Y.; Ma, M.; Liu, R. High strength ductile Ti-Fe alloy by carbon micro-alloying. J. Alloy. Compd. 2016, 688, 376-379. [CrossRef] 
3. Liu, Y.J.; Wang, H.L.; Li, S.J.; Wang, S.G.; Wang, W.J.; Hou, W.T.; Hao, Y.L.; Yang, R.; Zhang, L.C. Compressive and fatigue behavior of beta-type titanium porous structures fabricated by electron beam melting. Acta Mater. 2017, 126, 58-66. [CrossRef]

4. Shahmir, H.; Langdon, T.G. Using heat treatments, high-pressure torsion and post-deformation annealing to optimize the properties of Ti-6Al-4V alloys. Acta Mater. 2017, 141, 419-426. [CrossRef]

5. Xia, C.; Zhang, Z.; Feng, Z.; Pan, B.; Zhang, X.; Ma, M.; Liu, R. Effect of zirconium content on the microstructure and corrosion behavior of Ti-6Al-4V-xZr alloys. Corros. Sci. 2016, 112, 687-695. [CrossRef]

6. Fazel, M.; Salimijazi, H.R.; Golozar, M.A.; Garsivaz jazi, M.R. A comparison of corrosion, tribocorrosion and electrochemical impedance properties of pure $\mathrm{Ti}$ and Ti6Al4V alloy treated by micro-arc oxidation process. Appl. Surf. Sci. 2015, 324, 751-756. [CrossRef]

7. Lin, C.-M.; Kai, W.-Y.; Su, C.-Y.; Tsai, C.-N.; Chen, Y.-C. Microstructure and mechanical properties of Ti-6Al-4V alloy diffused with molybdenum and nickel by double glow plasma surface alloying technique. J. Alloy. Compd. 2017, 717, 197-204. [CrossRef]

8. Jing, R.; Liang, S.X.; Liu, C.Y.; Ma, M.Z.; Zhang, X.Y.; Liu, R.P. Structure and mechanical properties of Ti-6Al-4V alloy after zirconium addition. Mater. Sci. Eng. A 2012, 552, 295-300. [CrossRef]

9. Jing, R.; Liang, S.X.; Liu, C.Y.; Ma, M.Z.; Liu, R.P. Aging effects on the microstructures and mechanical properties of the Ti-20Zr-6.5Al-4V alloy. Mater. Sci. Eng. A 2013, 559, 474-479. [CrossRef]

10. Yang, Y.; Xia, C.; Feng, Z.; Jiang, X.; Pan, B.; Zhang, X.; Ma, M.; Liu, R. Corrosion and passivation of annealed Ti-20Zr-6.5Al-4V alloy. Corros. Sci. 2015, 101, 56-65. [CrossRef]

11. Yue, Y.; Dai, L.Y.; Zhong, H.; Tan, C.L.; Ma, M.Z.; Zhang, X.Y.; Liu, R.P. Enhanced mechanical properties for mill-annealed Ti-20Zr-6.5Al-4V alloy with a fine equiaxed microstructure. Mater. Sci. Eng. A 2016, 678, 286-290. [CrossRef]

12. Yue, Y.; Dai, L.Y.; Zhong, H.; Zhang, X.Y.; Liang, S.X.; Ma, M.Z.; Liu, R.P. Effect of microstructure on high cycle fatigue behavior of Ti-20Zr-6.5Al-4V alloy. J. Alloy. Compd. 2017, 696, 663-669. [CrossRef]

13. Zhang, B.; Zhang, X.; Zhang, X.Y.; Jia, Y.Z.; Ma, M.Z.; Liu, R.P.; Jing, Q. Effects of microstructure on the mechanical properties of a high-strength Ti20Zr6.5Al4V alloy. J. Alloy. Compd. 2018, 735, 2133-2141. [CrossRef]

14. Zhong, H.; Dai, L.Y.; Yue, Y.; Zhang, B.; Feng, Z.H.; Zhang, X.Y.; Ma, M.Z.; Khosla, T.; Xiao, J.; Liu, R.P. Friction and wear behavior of annealed Ti-20Zr-6.5Al-4V alloy sliding against 440c steel in vacuum. Tribol. Int. 2017, 109, 571-577. [CrossRef]

15. Liang, S.X.; Ma, M.Z.; Jing, R.; Zhang, X.Y.; Liu, R.P. Microstructure and mechanical properties of hot-rolled zrtialv alloys. Mater. Sci. Eng. A 2012, 532, 1-5. [CrossRef]

16. Shahzad, M.; Waqas, H.; Rafi ud, D.; Qureshi, A.H.; Wagner, L. The roles of Zn distribution and eutectic particles on microstructure development during extrusion and anisotropic mechanical properties in a Mg-Zn-Zr alloy. Mater. Sci. Eng. A 2015, 620, 50-57. [CrossRef]

17. Engler, O.; Randle, V. Introduction to Texture Analysis: Macrotexture, Microtexture, and Orientation Mapping, 2nd ed.; CRC Press: Boca Raton, FL, USA, 2009; p. 3. ISBN 978-1-4200-6356-3.

18. Gey, N.; Humbert, M. Specific analysis of ebsd data to study the texture inheritance due to the $\beta \rightarrow \alpha$ phase transformation. J. Mater. Sci. 2003, 38, 1289-1294. [CrossRef]

19. Hosford, W.F. The Mechanics of Crystals and Textured Polycrystals; Oxford University Press: Oxford, UK, 1993; p. 248.

20. Dick, T.; Cailletaud, G. Fretting modelling with a crystal plasticity model of Ti6Al4V. Comput. Mater. Sci. 2006, 38, 113-125. [CrossRef]

21. Fundenberger, J.J.; Philippe, M.J.; Wagner, F.; Esling, C. Modelling and prediction of mechanical properties for materials with hexagonal symmetry (zinc, titanium and zirconium alloys). Acta Mater. 1997, 45, 4041-4055. [CrossRef]

22. Guo, P.; Zhao, Y.; Zeng, W.; Hong, Q. The effect of microstructure on the mechanical properties of TC4-DT titanium alloys. Mater. Sci. Eng. A 2013, 563, 106-111. [CrossRef]

(C) 2018 by the authors. Licensee MDPI, Basel, Switzerland. This article is an open access article distributed under the terms and conditions of the Creative Commons Attribution (CC BY) license (http:/ / creativecommons.org/licenses/by/4.0/). 